\title{
25 Research Soure \\ Liver Inflammation and Fibrosis of HBeAg-Negative Patients in the Grey Zone
}

\author{
Renling Yao \\ Nanjing Drum Tower Hospital \\ Jian Wang \\ Nanjing Drum Tower Hospital \\ Jie Wei \\ Nanjing Drum Tower Hospital \\ Xiaomin Yan \\ Nanjing Drum Tower Hospital \\ Yuxin Chen \\ Nanjing Drum Tower Hospital \\ Juan Xia \\ Nanjing Drum Tower Hospital \\ Yue Yang
}

Nanjing Drum Tower Hospital

Kefang Yao

Nanjing Drum Tower Hospital Clinical College of Nanjing Medical University

Weihua Wu

Nanjing Drum Tower Hospital

Yong Liu

Nanjing Drum Tower Hospital

Jiacheng Liu

Nanjing Drum Tower Hospital Clinical college of Traditional Chinese and Western Medicine, Nanjing University of Chinese Medicine

Zhaoping Zhang

Nanjing Drum Tower Hospital

Weimao Ding

Huai'an NO.4 People's Hospital

\section{Rui Huang}

Nanjing Drum Tower Hospital

Chao Wu ( $\nabla$ dr.wu@nju.edu.cn )

Nanjing University Medical School Affiliated Nanjing Drum Tower Hospital 
Research article

Keywords: chronic hepatitis B, liver fibrosis, grey zone, HBeAg

Posted Date: October 6th, 2020

DOI: https://doi.org/10.21203/rs.3.rs-78876/v1

License: (c) (i) This work is licensed under a Creative Commons Attribution 4.0 International License. Read Full License 


\section{Abstract}

Background Few studies have reported the disease severity of HBeAg negative patients with chronic hepatitis $B(\mathrm{CHB})$ in the grey zone (GZ). This study aimed to investigate the degree of liver injury in the HBeAg negative $\mathrm{GZ}$ patients.

Methods One hundred and thirty-two treatment-naïve HBeAg negative GZ patients with HBV DNA $\geq 2,000$ $\mathrm{IU} / \mathrm{ml}$ and $\mathrm{ALT}<80 \mathrm{U} / \mathrm{L}$ who underwent liver biopsy were included. Liver histology was evaluated using the Scheuer classification system. Logistic regression analysis was used to identify independent risk factors of significant liver inflammation and fibrosis.

Results The median age of patients was 43.0 years and the median levels of HBV DNA was $4.3 \log _{10}$ $\mathrm{IU} / \mathrm{mL}$. The majority of patients $(65.2 \%)$ were male. The distributions of liver fibrosis stages of patients were as follows: S0, 7 (5.3\%); S1, 44 (33.3\%); S2, 32 (24.2\%); S3, 20 (15.2\%); and S4, 29 (22.0\%). The distributions of liver inflammation grades were: G0, 0 (0\%); G1, 40 (30.3\%); G2, 65 (49.2\%); G3, 32 (24.2\%); and G4, 20 (15.2\%). The serum AST $(1.051,95 \% \mathrm{Cl} 1.008-1.096, \mathrm{P}=0.019)$ and HBV DNA $(1.579,95 \% \mathrm{Cl}$ $1.023-2.438, P=0.039)$ levels were independently risk factors of significant liver fibrosis. The serum AST $(1.072,95 \% \mathrm{Cl} 1.023-1.124, \mathrm{P}=0.004)$ was the only independently risk factor of significant liver inflammation. Serum HBV DNA and AST had moderate accuracy of predicting significant liver fibrosis and inflammation.

Conclusion Substantial patients exhibited significant liver injury in HBeAg negative GZ patients. High HBV DNA and AST levels were two independent risk factors of significant liver injury.

\section{Background}

Chronic hepatitis B virus (HBV) infection remains to be one of the most serious health burden, and more than 350 million people are chronically infected with hepatitis B virus (HBV) worldwide. ${ }^{1}$ Chronic hepatitis $B(\mathrm{CHB})$ can result in a series of clinical manifestations, including liver fibrosis, liver cirrhosis, liver failure and hepatocellular carcinoma (HCC) ${ }^{2}$ Chronic HBV infection is a dynamic disease disease course, which can be divided in to several different immune states based on the current guidelines (add the ref). Hepatitis B e antigen (HBeAg) status, HBV DNA and alanine transaminase (ALT) levels are three crucial factors in dividing the diseases phases of patients with chronic HBV infection. ${ }^{3-5}$ However, since a substantial portion of CHB patients could not be categorized into any phase as defined by the current guidelines, ${ }^{3-5}$ these disease states were described as grey zone (GZ) ${ }^{6,7}$ Among these, much attention has been paid to HBeAg negative GZ patients.

The definition of GZ remains inconsistent for HBeAg negative patients. ${ }^{6,7}$ Both HBV DNA $\geq 2,000 \mathrm{IU} / \mathrm{ml}$ and normal or mild elevated ALT levels were proposed as common criteria in HBeAg negative GZ patients in previous studies. ${ }^{6,7}$ According to the international guidelines, $\mathrm{HBeAg}$ negative $\mathrm{CHB}$ patients with detectable HBV DNA and significant liver histology injury should be treated regardless of ALT level. ${ }^{3-5}$ 
Therefore, the severity of liver damage and identifying the risk factors is critical for the management of HBeAg negative GZ patients. However, few studies reported the severity of liver injury in HBeAg negative GZ patients. A retrospective study revealed that HBeAg negative GZ? patients with high level HBV DNA and normal ALT was associated with significant liver inflammation and fibrosis. ${ }^{8}$ However, more than half of the patients combined with fatty liver disease and the sample size is relatively small. ${ }^{8}$

Additional study is required to clarify the diseases severity of HBeAg negative GZ patients to guide the clinical practice. Therefore, this study aimed to investigate the severe degree of liver inflammation and fibrosis in the HBeAg negative GZ patients.

\section{Methods}

\section{Study population}

One thousand and five consecutive treatment-naïve cases of chronic HBV infection who underwent liver biopsy in two medical centers (Nanjing Drum Tower Hospital and Huai'an No. 4 People's Hospital) during April 2004 and July 2019 were included. The diagnostic criteria of CHB was hepatitis B surface antigen (HBsAg) being positive for at least 6 months. The enrolled criteria were ALT $<80 \mathrm{U} / \mathrm{L}, \mathrm{HBV}$ DNA $\geq$ $2000 \mathrm{IU} / \mathrm{ml}$ and HBeAg negative. ${ }^{6,9}$ Patients who meet the following conditions were excluded: (1) HCC or/and other malignancy; (2) Other causes of chronic liver diseases: other viral hepatitis, nonalcoholic fatty liver disease, immune-related liver disease and hereditary metabolic liver disease, acquired immune deficiency syndrome and syphilis; (3) alcohol abuse per day? ( $>40 \mathrm{~g}$ for men and $>20 \mathrm{~g}$ for women).

This study protocol was accorded with Declaration of Helsinki and was conducted with the approval of the Ethics Committee of the Nanjing Drum Tower Hospital and Huai'an No. 4 People's Hospital (protocol number?).

\section{Laboratory assays and liver biopsy}

Biopsy specimens were fixed in $10 \%$ formalin and embedded in paraffin. The specimens were evaluated by two pathologists regardless of clinical characteristics. Liver fibrosis and inflammation activity were assessed by Scheuer scoring system. ${ }^{10}$ Liver fibrosis was staged on a scale from S0 to S4, and S2-S4 was defined as significant fibrosis. ${ }^{10}$ Liver inflammation was graded on a scale from G0 to G4, and G2G4 was defined as significant inflammation. ${ }^{10}$ Liver function and blood routine tests were detected within two weeks before liver biopsy. The upper limit of normal (ULN) of ALT was $40 \mathrm{U} / \mathrm{L}$. HBsAg and HBeAg were measured by the enzyme-linked immunosorbent assay. The detection limitation of HBV DNA was $500 \mathrm{IU} / \mathrm{ml}$ in our study.

\section{Statistical analysis}


Categorical variables and continuous variables were presented as percentage and median (interquartile range (IQR)), respectively. Baseline characteristics were compared by Chi-square test for categorical variables and Mann-Whitney $U$ test was used to compare continuous variables. The related risk factors of significant fibrosis and inflammation were identified by logistic regression analysis. The correlation between clinical parameters and pathological damage degree was performed by Spearman's correlation analysis. Statistical significance was taken as $P<0.05$. SPSS software version 22.0 was used for the statistical analyses (SPSS Inc., Chicago, IL, United States).

\section{Results}

\section{Characteristics of the study patients}

One thousand and five consecutive treatment-naïve cases of CHB who underwent liver biopsy were included in our study. A total of eight hundreds seventy three patients was excluded based on the above inclusion and exclusion criteria. Among them, two hundred and sixty-seven patients were excluded based on exclusion criteria, and 606 patients with HBeAg positive and/or HBV DNA $\leq 2,000 \mathrm{IU} / \mathrm{ml}$ and/or ALT $\geq$ $80 \mathrm{U} / \mathrm{L}$ were also excluded. Eventually, 132 patients were included for the analysis (Fig. 1). The median age was 43.0 (IQR 37.0-49.0) years, and the majority of patients (65.2\%) were male. The median of PLT, ALT, AST, ALB and HBV DNA levels were 163.0 (IQR 126.5-197.5) × 10\%/L, 40.0 (IQR 26.5-53.9) U/L, 31.0 (IQR 25.0-39.5) U/L, 45.0 (IQR 40.6-47.5) g/L and 4.3 (IQR 3.8-5.2) $\log _{10} \mathrm{IU} / \mathrm{ml}$, respectively (Table 1).

Table 1

Baseline characteristics of study population.

\begin{tabular}{|ll|}
\hline Variables & $\mathbf{n}(\%)$ or median (IQR) \\
\hline Age $(\mathrm{yr})$ & $43.0(37.0,49.0)$ \\
\hline Male $(\%)$ & $86(65.2)$ \\
\hline PLT $\left(\times 10^{9} / \mathrm{L}\right)$ & $163.0(126.5,197.5)$ \\
\hline TB $(\mu \mathrm{mol} / \mathrm{L})$ & $13.8(10.918 .2)$ \\
\hline ALT $(\mathrm{U} / \mathrm{L})$ & $40.0(26.5,53.9)$ \\
\hline AST $(\mathrm{U} / \mathrm{L})$ & $31.0(25.0,39.5)$ \\
\hline GGT $(\mathrm{U} / \mathrm{L})$ & $26.0(18.0,47.0)$ \\
\hline ALB $(\mathrm{g} / \mathrm{L})$ & $45.0(40.6,47.5)$ \\
\hline GLB $(\mathrm{g} / \mathrm{L})$ & $27.2(24.8,30.8)$ \\
\hline HBV DNA (log 10 IU/mL) & $4.3(3.8,5.2)$ \\
\hline PLT: platelets; TB: total bilirubin; ALT: alanine aminotransferase; AST: aspartate aminotransferase; & \\
\hline GGT: gamma-glutamyl transpeptidase; ALB: albumin; GLB: globulin.
\end{tabular}




\section{Liver inflammation and fibrosis of HBeAg-negative GZ patients}

The distributions of fibrosis stages were listed as follows: 7 (5.3\%) patients in S0, 44 (33.3\%) patients in S1, 32 (24.2\%) patients in S2, 20 (15.2\%) patients in S3, and 29 (22.0\%) patients in S4, respectively. More than half of the patients $(n=81,61.4 \%)$ had significant liver fibrosis. The distributions of inflammation grades were as follows: none patients in $\mathrm{G0}, 40$ (30.3\%) patients in $\mathrm{G} 1,65(49.2 \%)$ patients in $\mathrm{G} 2,32$ (24.2\%) patients in $\mathrm{G} 3$, and $20(15.2 \%)$ patients in G4, respectively. A total of $92(69.7 \%)$ patients had significant liver inflammation (Fig. 2).

\section{Risk factors of significant liver fibrosis and inflammation}

The PLT $(0.992,95 \% \mathrm{Cl} 0.986-0.998, \mathrm{P}=0.01)$, AST $(1.063,95 \% \mathrm{Cl} 1.021-1.107, \mathrm{p}=0.003)$ and HBV DNA $(1.811,95 \% \mathrm{Cl} 1.193-2.750, \mathrm{P}=0.005)$ were associated with significant liver fibrosis by univariate logistic regression analysis. Further multivariate logistic regression analysis showed that the AST $(1.051,95 \% \mathrm{Cl}$ 1.008-1.096, $\mathrm{P}=0.019)$ and HBV DNA $(1.579,95 \% \mathrm{Cl} 1.023-2.438, \mathrm{P}=0.039)$ were independent risk factors of significant liver fibrosis (Table 2). Univariate logistic regression analysis revealed that ALT $(1.025,95 \% \mathrm{Cl} 1.001-1.049, \mathrm{P}=0.039)$, AST $(1.070,95 \% \mathrm{Cl} 1.022-1.121, \mathrm{P}=0.004)$ and GGT $(1.023$, $95 \% \mathrm{Cl} 1.004-1.042, \mathrm{P}=0.017)$ were correlated with significant liver inflammation, while AST $(1.072$, $95 \% \mathrm{Cl} 1.023-1.124, \mathrm{P}=0.004)$ was the only independent risk factor of significant liver inflammation (Table 3). In addition, we further analyzed the correlation in several clinical indexes, liver fibrosis stages and inflammation grades. The AST $(r=0.273, P=0.002)$ and HBV DNA $(r=0.248, P=0.004)$ levels were positively correlated with liver fibrosis stages, while ALT $(r=0.189, P=0.030)$, AST $(r=0.280, P=0.001)$ and HBV DNA $(r=0.179, P=0.04)$ levels were positively correlated with liver inflammation grades (Table 4). 
Table 2

Logistic regression analysis of clinical parameters associated with significant liver fibrosis in $\mathrm{HBeAg}$ negative patients in the grey zone.

\begin{tabular}{|c|c|c|c|c|}
\hline \multirow[t]{2}{*}{ Variables } & \multicolumn{2}{|l|}{ Univariate } & \multicolumn{2}{|l|}{ Multivariate } \\
\hline & OR $(95 \% \mathrm{Cl})$ & $P$ value & OR (95\% Cl) & $P$ value \\
\hline Age (yr) & $0.991(0.956,1.027)$ & 0.617 & & \\
\hline Sex & $0.897(0.428,1.876)$ & 0.772 & & \\
\hline $\operatorname{PLT}\left(\times 10^{9} / \mathrm{L}\right)$ & $0.992(0.986,0.998)$ & 0.01 & & \\
\hline TB $(\mu \mathrm{mol} / \mathrm{L})$ & $1.001(0.957,1.047)$ & 0.965 & & \\
\hline $\operatorname{ALB}(\mathrm{g} / \mathrm{L})$ & $0.935(0.852,1.026)$ & 0.154 & & \\
\hline $\operatorname{GLB}(\mathrm{g} / \mathrm{L})$ & $1.049(0.969,1.136)$ & 0.234 & & \\
\hline $\operatorname{ALT}(\mathrm{U} / \mathrm{L})$ & $1.021(0.999,1.042)$ & 0.059 & & \\
\hline AST (U/L) & $1.063(1.021,1.107)$ & 0.003 & $1.051(1.008,1.096)$ & 0.019 \\
\hline GGT (U/L) & $1.006(0.996,1.017)$ & 0.238 & & \\
\hline HBV DNA $\left(\log _{10} \mathrm{IU} / \mathrm{mL}\right)$ & $1.811(1.193,2.750)$ & 0.005 & $1.579(1.023,2.438)$ & 0.039 \\
\hline
\end{tabular}


Table 3

Logistic regression analysis of clinical parameters associated with significant liver inflammation in HBeAg-negative patients in the grey zone.

\begin{tabular}{|c|c|c|c|c|}
\hline \multirow[t]{2}{*}{ Variables } & \multicolumn{2}{|l|}{ Univariate } & \multicolumn{2}{|l|}{ Multivariate } \\
\hline & OR $(95 \% \mathrm{Cl})$ & $P$ value & OR $(95 \% \mathrm{Cl})$ & $P$ value \\
\hline Age (yr) & $0.969(0.932,1.007)$ & 0.113 & & \\
\hline Sex & $1.010(0.463,2.199)$ & 0.981 & & \\
\hline $\operatorname{PLT}\left(\times 10^{9} / \mathrm{L}\right)$ & $0.996(0.990,1.002)$ & 0.244 & & \\
\hline TB $(\mu \mathrm{mol} / \mathrm{L})$ & $1.017(0.967,1.070)$ & 0.503 & & \\
\hline $\operatorname{ALB}(g / L)$ & $1.016(0.928,1.113)$ & 0.734 & & \\
\hline GLB $(g / L)$ & $1.084(0.991,1.186)$ & 0.079 & & \\
\hline $\operatorname{ALT}(\mathrm{U} / \mathrm{L})$ & $1.025(1.001,1.049)$ & 0.039 & & \\
\hline AST (U/L) & $1.070(1.022,1.121)$ & 0.004 & $1.072(1.023,1.124)$ & 0.004 \\
\hline GGT (U/L) & $1.023(1.004,1.042)$ & 0.017 & & \\
\hline HBV DNA $\left(\log _{10} \mathrm{IU} / \mathrm{mL}\right)$ & $1.522(0.995,2.328)$ & 0.053 & & \\
\hline
\end{tabular}

Table 4

Correlation between different clinical parameters and liver inflammation and fibrosis of HBeAg-negative patients in the grey zone

\begin{tabular}{|lllll|}
\hline Correlation analysis & \multicolumn{2}{l}{ Fibrosis stages } & \multicolumn{2}{l|}{ Inflammation grades } \\
\cline { 2 - 5 } & $\mathbf{R}$ & $\mathbf{P}$ & $\mathbf{R}$ & $\mathbf{P}$ \\
\hline Age & -0.060 & 0.492 & -0.135 & 0.122 \\
ALT & 0.161 & 0.066 & 0.189 & 0.030 \\
AST & 0.273 & 0.002 & 0.280 & 0.001 \\
HBV DNA & 0.248 & 0.004 & 0.179 & 0.040 \\
HBsAg & 0.032 & 0.747 & 0.033 & 0.742 \\
\hline ALT: alanine aminotransferase; AST: aspartate aminotransferase; HBsAg: hepatitis B surface antigen. \\
\hline
\end{tabular}




\section{Diagnostic accuracy of HBV DNA and AST for the prediction of significant fibrosis and inflammation.}

The area under the receiver operating characteristic curves (AUROCs) of HBV DNA and AST for predicting significant fibrosis were $0.647(95 \% \mathrm{Cl} 0.553-0.741, \mathrm{P}=0.005)$ and $0.662(95 \% \mathrm{Cl} 0.567-0.756, \mathrm{P}=0.002)$, and the optimal cut-off value was $5.0 \log _{10} \mathrm{IU} / \mathrm{ml}$ and $28.3 \mathrm{U} / \mathrm{L}$, respectively. For predicting significant inflammation, the AST exhibited the AUROCs of $0.676(95 \% \mathrm{Cl} 0.578-0.773, \mathrm{P}=0.001)$, with an optimal cut-off value of $28.0 \mathrm{U} / \mathrm{L}$ (Fig. 3, Table 5).

Table 5.

Diagnostic accuracy of HBV DNA and AST for the prediction of significant fibrosis and inflammation in HBeAg-negative patients in the grey zone

\begin{tabular}{|lcllllll|}
\hline & $\begin{array}{c}\text { Optimized } \\
\text { cutoff }\end{array}$ & $\begin{array}{l}\text { Sensitivity } \\
(\%)\end{array}$ & $\begin{array}{l}\text { Specificity } \\
(\%)\end{array}$ & AUC $(95 \% \mathrm{Cl})$ & LR + & LR - & $\begin{array}{l}\text { P } \\
\text { value }\end{array}$ \\
\hline Significant fibrosis & & & & & & \\
\hline $\begin{array}{l}\text { HBV DNA } \\
\left(\log _{10} \mathrm{IU} / \mathrm{mL}\right)\end{array}$ & 5.0 & 40.74 & 90.20 & $\begin{array}{l}0.647(0.553, \\
0.741)\end{array}$ & 4.157 & 0.657 & 0.005 \\
AST (U/L) & 28.3 & 69.14 & 58.82 & $\begin{array}{l}0.662 \\
(0.567,0.756)\end{array}$ & 1.679 & 0.525 & 0.002 \\
\hline Significant inflammation & & & & & & \\
\hline AST (U/L) & 28.0 & 75.00 & 62.50 & $\begin{array}{l}0.676(0.578, \\
0.773)\end{array}$ & 2.000 & 0.400 & 0.001 \\
\hline
\end{tabular}

AUC: area under the receiver operating characteristic curve; Cl: confidence interval; LR-: negative likelihood ratio; LR+: positive likelihood ratio; AST: aspartate aminotransferase.

\section{Discussion}

The assessment of severity of liver injury is an important step for the clinical management of $\mathrm{HBeAg}$ negative $\mathrm{GZ}$ patients to identify those who require antiviral treatment and avoid severe complications. ${ }^{3,11}$ However, few studies reported the distributions of inflammation and fibrosis stages and the risk factors of significant liver injury in HBeAg negative GZ patients. Our study found that $92(69.7 \%)$ patients showed significant liver inflammation and $81(61.4 \%)$ patients presented significant liver fibrosis, suggesting that about two thirds of patients had significant liver damage. According to recommendations of international guidelines, these patients should be treated as soon as possible. ${ }^{3-5}$ However, only a few patients received liver biopsy in clinical practice. Thus, the majority of HBeAg negative GZ patients with significant liver injury were not treated timely. A similar study was reported by Park et al. revealed that $60 \%$ patients had significant liver fibrosis and $61.9 \%$ patients had significant liver inflammation in CHB patients with ALT< 2 ULN and high HBV DNA level (> 20,000 IU/ml) ${ }^{12}$ However, the majority of patients (81.2\%) were HBeAg positive in that study. Kumor et al. demonstrated that high HBV DNA levels and persistently normal ALT 
was an independently risk factor of significant liver fibrosis and inflammation in $\mathrm{HBeAg}$ negative $\mathrm{CHB}$ patients. ${ }^{8}$ Therefore, these results suggested that the absence of significant ALT elevation does not indicate the absence of significant liver injury in HBeAg negative GZ patients.

Furthermore, the present study further analyzed the risk factors of significant liver inflammation and fibrosis in HBeAg negative GZ patients. Our results revealed that high levels of AST and HBV DNA were associated with severe liver fibrosis and AST level was also positively correlated with advanced lavel of liver inflammation grade. Though the ALT level was considered as the most common used indicator of liver disease activity and severity in CHB patients, numerous studies have demonstrated that ALT was not a significant factor associated with liver inflammation and fibrosis in HBeAg negative CHB patients. ${ }^{13,14}$ Our study also found that ALT was not associated with liver inflammation grades nor fibrosis stages in HBeAg negative GZ patients. In contrast, our results suggested that AST can be a substitute of ALT for reflecting disease activity and severity in $\mathrm{HBeAg}$ negative $\mathrm{GZ}$ patients. Consistent with previous studies ${ }^{15,16}$, high HBV DNA level was the most significant factor associated with significant liver fibrosis in our study. A prospective study revealed that the high level of HBV DNA was the strongest predictor for liver disease progression to cirrhosis in the future. ${ }^{16}$ Mohamadnejad et al. reported that HBV DNA could predict significant liver fibrosis with a sensitivity of $82 \%$ and specificity of $70 \%$ in HBeAg negative patients. ${ }^{15}$ Taken together, these results suggested that patients with high level HBV DNA should be closely monitored regardless of ALT level.

This study had several limitations. Firstly, the sample size was relatively small and patients were only enrolled from two medical centers. Thus, the results should be further validated by multi-center study with large samples. Secondly, the long-term prognosis of HBeAg negative GZ patients was not analyzed. Further study is needed to investigate the incidence of liver-related adverse events among these patients.

\section{Conclusion}

In summary, our study showed that more than half of the patients exhibited significant liver injury in HBeAg negative GZ patients. High HBV DNA and AST levels were two independently risk factors of significant liver injury for HBeAg-negative GZ patients.

\section{Abbreviations}

$\mathrm{CHB}$, chronic hepatitis $\mathrm{B} ; \mathrm{GZ}$, grey zone; $\mathrm{HBV}$, hepatitis B virus; $\mathrm{CHB}$, Chronic hepatitis $\mathrm{B}$; $\mathrm{HCC}$, hepatocellular carcinoma; HBeAg, Hepatitis B e antigen; ALT, alanine transaminase; HBsAg, hepatitis B surface antigen; ULN, upper limit of normal; IQR, interquartile range; AUROCs, area under the receiver operating characteristic curves.

\section{Declarations}

Acknowledgements 
Not applicable.

\section{Funding}

The study was supported from the National Science and Technology Major Project of China (2018ZX10302205), National Natural Science Foundation of China (81672025 and 81702011), Medical Science and Technology Development Foundation of Nanjing (ZDX16004), Jiangsu Science and Technology Development Plan (BE2017605), Jiangsu Provincial Medical Innovation Team (CXTDA2017005) and Nanjing Medical Science and Technique Development Foundation (QRX17121). The sponsors had no contribution in the study design, data collection, analysis, writing manuscript.

\section{Availability of data and materials}

The dataset generated or analyzed during the current study is available from the corresponding author on reasonable request.

\section{Authors' contributions}

$\mathrm{CW}$ and $\mathrm{RH}$ designed the study and revised the manuscript; RY, JW and JW analyzed the data and wrote the manuscript; $X Y, Y C, J X, Y Y, K Y, W W, Y L, J L, Z Z, W D$ collated the data. All authors read and approved the final manuscript.

\section{Ethics approval and consent to participate}

The study was approved by the Ethics Committees of the Nanjing Drum Tower Hospital and Huai'an No. 4 People's Hospital. The ethics committee waived the need for a written informed consent because this study was retrospective.

\section{Consent for Publication}

Not applicable

\section{Competing interests}

The authors have declared that no conflicts of interest exist.

\section{References}

1. Schweitzer A, Horn J, Mikolajczyk RT, et al. Estimations of worldwide prevalence of chronic hepatitis B virus infection: a systematic review of data published between 1965 and 2013. Lancet. 2015;386:1546-1555.

2. Lee WM. Hepatitis B virus infection. N Engl J Med. 1997;337:1733-1745.

3. Terrault NA, Bzowej NH, Chang KM, et al. AASLD guidelines for treatment of chronic hepatitis B. Hepatology. 2016;63:261-283. 
4. Sarin SK, Kumar M, Lau GK, et al. Asian-Pacific clinical practice guidelines on the management of hepatitis B: a 2015 update. Hepatol Int. 2016;10:1-98.

5. European Association for the Study of the Liver. EASL 2017 Clinical Practice Guidelines on the management of hepatitis B virus infection. J Hepatol. 2017;67:370-398.

6. Bonacci $\mathrm{M}$, Lens $\mathrm{S}$, Mariño Z, et al. Anti-viral therapy can be delayed or avoided in a significant proportion of HBeAg-negative Caucasian patients in the Grey Zone. Aliment Pharmacol Ther. 2018;47:1397-1408.

7. Gil-García Al, Madejón A, Francisco-Recuero I, et al. Prevalence of hepatocarcinoma-related hepatitis B virus mutants in patients in grey zone of treatment. World J Gastroenterol. 2019;25:5883-5896.

8. Kumar M, Sarin SK, Hissar S, et al. Virologic and histologic features of chronic hepatitis B virusinfected asymptomatic patients with persistently normal ALT. Gastroenterology. 2008;134:13761384.

9. Choi GH, Kim GA, Choi J, et al. High risk of clinical events in untreated HBeAg-negative chronic hepatitis B patients with high viral load and no significant ALT elevation. Aliment Pharmacol Ther. 2019;50:215-226.

10. Scheuer PJ. Classification of chronic viral hepatitis: a need for reassessment. J Hepatol. 1991;13:372-374.

11. Guidelines for the Prevention, Care and Treatment of Persons with Chronic Hepatitis B Infection. Geneva: World Health Organization; 2015.

12. Park JY, Park YN, Kim DY, et al. High prevalence of significant histology in asymptomatic chronic hepatitis B patients with genotype C and high serum HBV DNA levels. J Viral Hepat. 2008;15:615621.

13. Keeffe EB, Dieterich DT, Han SH, et al. A treatment algorithm for the management of chronic hepatitis B virus infection in the United States. Clin Gastroenterol Hepatol. 2004;2:87-106.

14. Yuen MF, Yuan HJ, Wong DK, et al. Prognostic determinants for chronic hepatitis B in Asians: therapeutic implications. Gut. 2005;54:1610-1614.

15. Mohamadnejad M, Montazeri G, Fazlollahi A, et al. Noninvasive markers of liver fibrosis and inflammation in chronic hepatitis B-virus related liver disease. Am J Gastroenterol. 2006;101:25372545.

16. lloeje UH, Yang HI, Su J, et al. Predicting cirrhosis risk based on the level of circulating hepatitis B viral load. Gastroenterology. 2006;130:678-686.

\section{Figures}




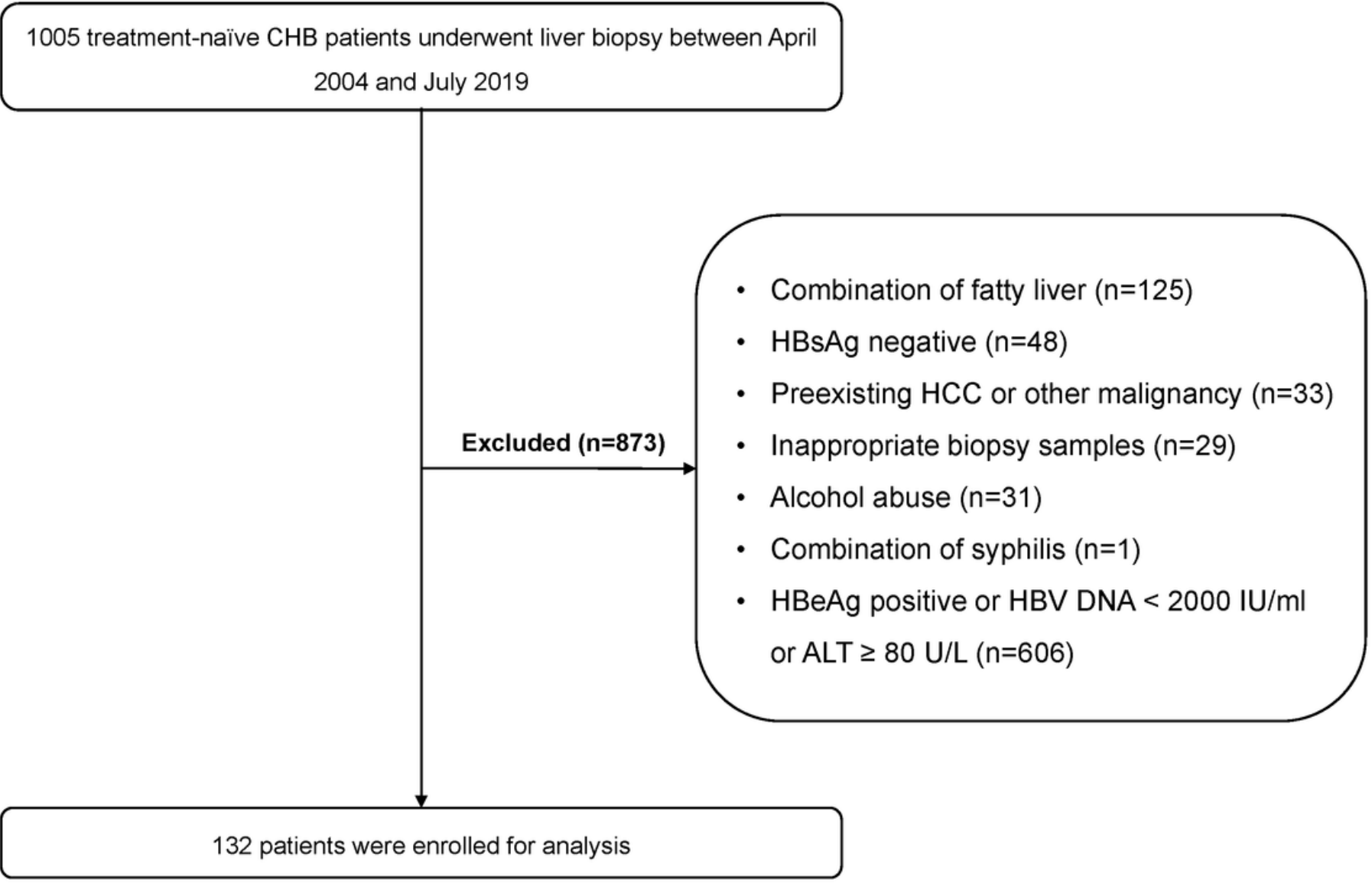

Figure 1

Flow diagram describing the selection of our study cohort. 
A

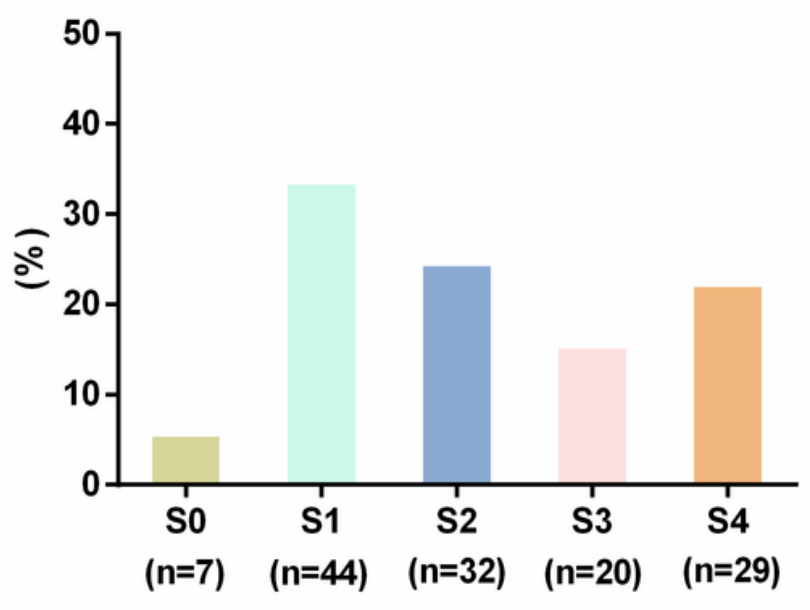

Fibrosis stage
B

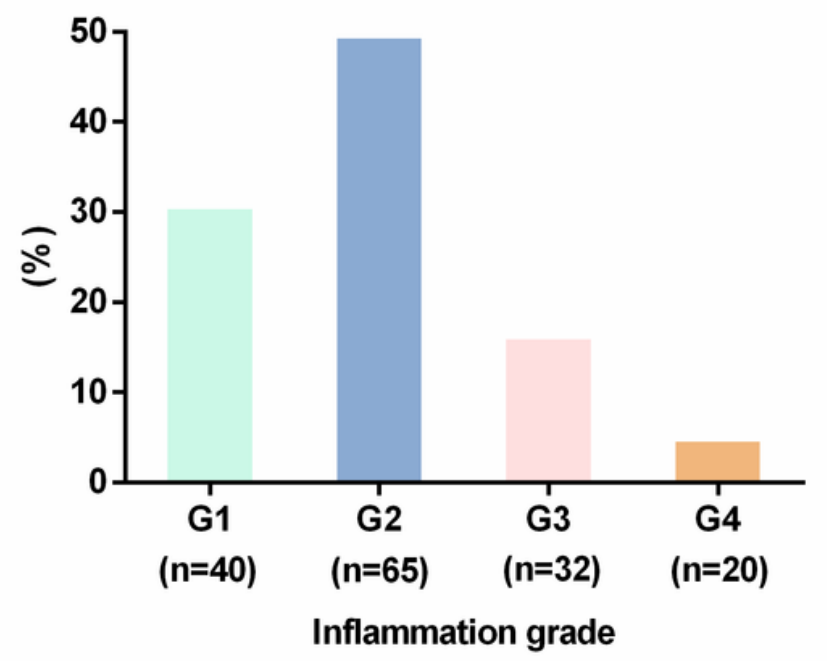

Figure 2

Distribution of liver fibrosis stages $(A)$ and inflammation grades $(B)$ in HBeAg negative patients with $\mathrm{CHB}$ in the grey zone. 
A

Significant fibrosis $(\geq \mathrm{S} 2)$

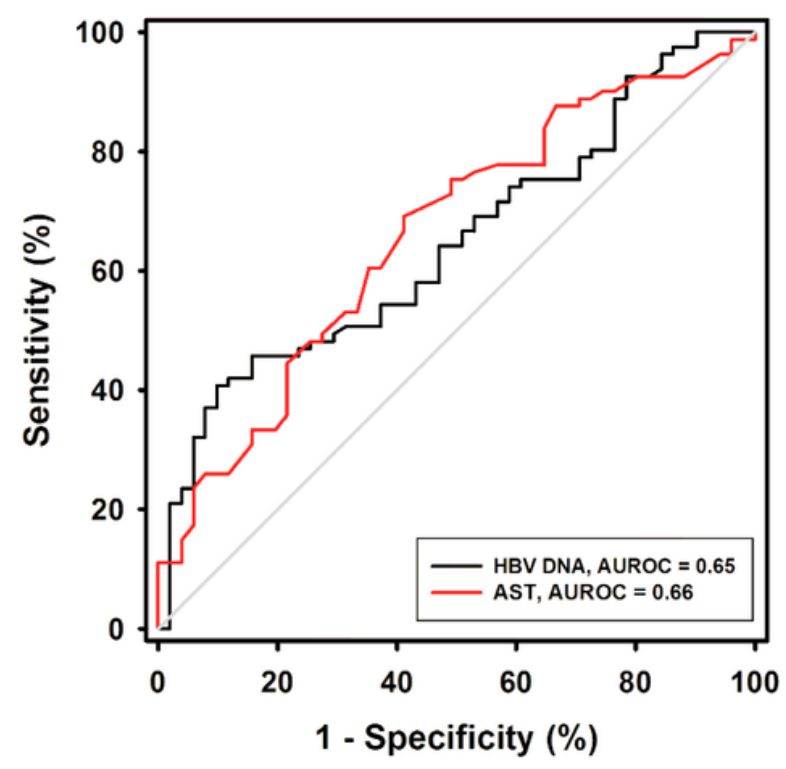

B Significant inflammation ( $\geq$ G2)

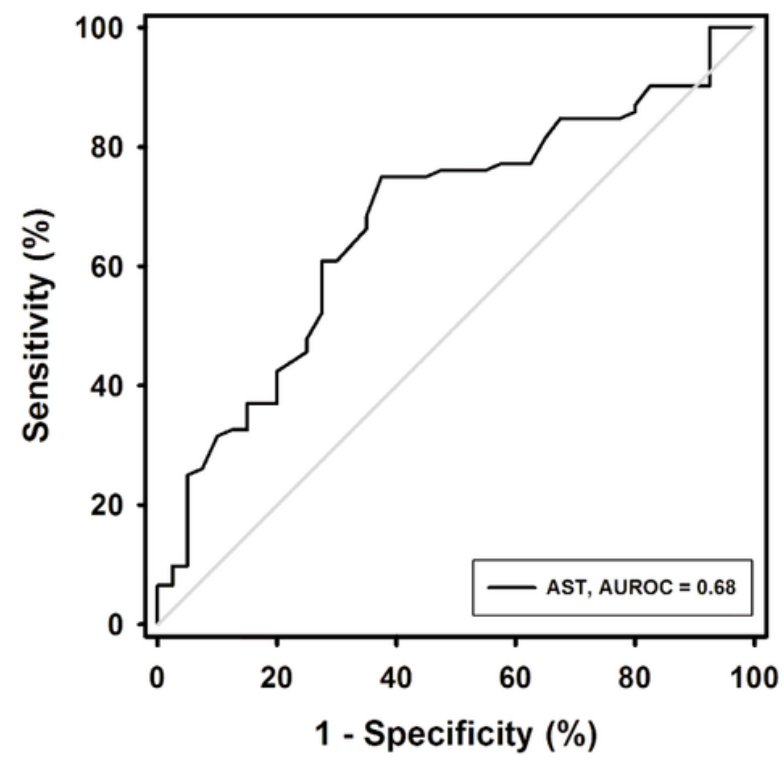

\section{Figure 3}

Diagnostic accuracy of HBV DNA and AST for the prediction of significant fibrosis (A) and inflammation (B). 